\title{
Fundamental Shifts in Strategic Thinking Concepts and their Teaching Implications
}

\author{
Prof Dr M S S El Namaki \\ Dean, VU Switzerland. \\ Founder and Past Dean, Maastricht School of Management, MSM, the Netherlands. \\ CEO, Association for Accreditation of International Business Education aaime.net
}

\section{The problem}

Powerful forces of disruption are penetrating the core concepts of strategic thinking and the strategy education industry.

Traditional strategic thinking literature and instruction material rest on a solid base of concepts developed by authors from Ansoff and Drucker to Porter, Mintzberg and Prahalad. Their concepts lasted for decades and their literature is a standard feature of business school strategy teachings until this very day. Disruptive forces are changing this situation, however, Generic and functional disruptive forces from boundary-breaking technologies, and norm shaking sociology to rule-breaking economics and unsettling political shifts, have gone a long way towards introducing a new paradigm.

The following article provides an attempt at identifying those concepts worn out by new realities or end game concepts, and those others constituting a novel thrust.

The article draws a picture of possible future consequences as well. Those include research prospects, curricula implications and competency gaps.

\section{The forces of disruption}

The author contends that powerful forces of disruption have undermined many of the conceptual foundations of strategic thinking as they have evolved over the past decades. This disruption was as much generic as functional (see figure) (El Namaki, 2018). 


\section{Figure 1: Domains of disruption: a conceptual framework}

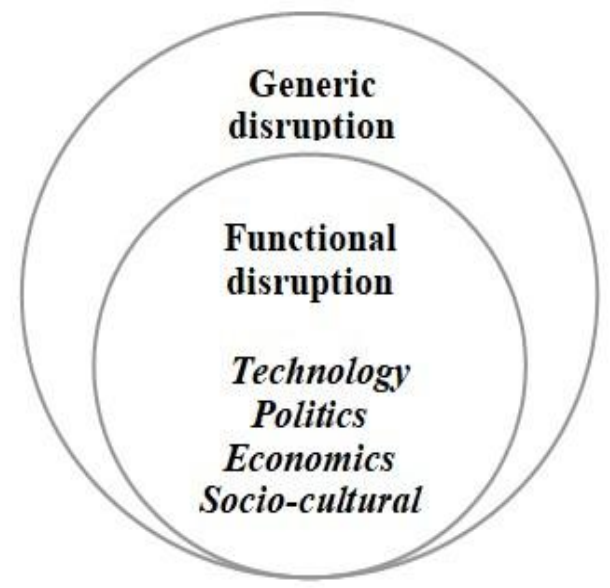

Source: E1 Namaki, 2018

\section{- Generic disruption}

Generic disruption is a force or a bundle of forces that cut across systems and reconfigure constituent elements. Generic disruption cuts across industries, markets organizations and functions. It does not arise from competitors in the same industry or even from companies with a remotely similar business model but from the distant and previously unidentified driving force. It blends forces drawn from separate seemingly unrelated strands of science, to create dramatic value-enhancing and rule changing propositions. (E1 Namaki, 2018)

\section{- Functional disruption}

Functional disruption is a force that undermines one or the other aspect of systemrelated functional performance parameters. One can think of it in terms of four segments; a technology segment, an economic segment, a political segment and a sociology segment with each segment having its own driving forces.

\section{- Technology: the 4th industrial revolution}

Technologies that significantly alter the way that businesses or entire industries operate, are labelled disruptive and seem to be a leading source of functional disruption (Schwab, 2016)

\section{○ Politics: Neo-globalization.}

Premises of a new paradigm for globalization are challenging traditional frameworks and introducing disruption to international economic policies, strategies and institutions (El Namaki, 2017).

\section{- Economics: Excessive capitalism}

Capital markets provide the core and the driving force of capitalist policies and practices but they have also induced disruptive economic instability and at times failure. (El Namaki, 2015) (El Namaki, 2012). 


\section{○ Socio-culture: Social media}

Social media or software-based technologies that facilitate the creation and sharing of all forms of expression via virtual communities and networks, is proving to be a potent disruption vehicle (Forbes, Oct 23, 2016).

\section{How were strategic thinking premises disrupted?}

The wide variety of disruption forces outlined above had a tangible impact on the validity and applicability of several core strategic management concepts.

\section{Porter's Five force analysis}

Structural flaws were observed in Porter's five force analysis from the early days. Those included lack of pertinent definitions of industry, competition and competitive advantage (Meyer R, Volbeerda H, 1997) as well as the assumption that buyers, competitors, and suppliers are unrelated and do not interact and collude. One of the most serious flaws today, however, is the role of capital markets. Capital markets events have had, for decades, too profound an impact on the scope, reach and impact of the five forces. Capital markets have disrupted corporate strategies ever since Reagan's deregulation (Boskin, 1987), the investment and structured finance debacle of 2008 (El Namaki, 2014) (Nilofer, 2012) and, more recently, the Corona inflicted farreaching monetary policies. Capital markets continue to undermine the influence and impact of the five forces until this very day.

\section{Competitive advantage}

Competitive advantage is the child of Porter's competitive strategies. It essentially connotes the existence of factors allowing a company to provide better performance than rivals. Cost, branding, quality, supply chain all induce a competitive advantage. The concept lost lustre when the roots of advantage i.e. cost and brand positioning, for example, were overtaken by disruptive advances in technology and a fast pace of market force shifts. The competitive advantage became transient, not sustainable, and a new set of assumptions was needed. Within-industry competition lost the sense of threat that made it the incumbent's most significant competitive danger. (Forbes, 2013)

\section{Strategy formulation: BCG matrix}

The concept of the growth-share matrix was conceived in 1970 as a resource allocation and strategy formulation instrument. The question arose however as to the congruence of the matrix with the rapid disruptive pace and unpredictable nature of today's marketplace. Products, markets, and business models shifted grounds leading to a search for new "question marks". and a systematic grooming promising ones into" stars". All within an environment that demands speed and precision. And an environment that has to deal with a changing concept of product and product function. By (Martin Reeves, Sandy Moose, and Thijs Venema BCG Classics Revisited: The Growth Share Matrix)

\section{Strategic behaviour}

Expressions of strategic behaviour have stalled over the past decade or decades. Disruptive product innovation and market shifts provided the backbone of those 
expressions. These expressions have stimulated typical patterns of strategic behaviour as leveraged acquisition and enhanced mergers. Capital markets became the underlying trigger of strategic moves (private equity industry); ruthless restructurings such as the road to survival; concentration as the medium for strategic competitive advantage and predictable exit.

Business environments are now so diverse that we need different approaches to strategy in different circumstances. The classical approach to strategy is no longer the ultimate wisdom. Corporations, especially high concentration players, need to deploy multiple approaches to strategy in different parts of their business. (McGrath, 2013)

\section{Scenario building}

Scenario building assumes the existence of different states of a variable or a group of variables and assembles different variable-specific permutations of plausible situations and problems that could exist over time. Generic and functional disruptions of the types discussed above undermine this scenario building concept, however. There is the element of content and the issue of speed. Disruption forces of, for instance, technology, are deep, far-reaching and fast. All three elements undermine the usefulness as well as the validity of scenarios based on today's or yesterday's data and knowledge. Long applied scanning processes leading to the composition of the different scenario "scenes" are replaced by more conducive technologies, moreover.

\section{Leadership}

The concept of leadership has gained considerable attention and analysis both anecdotal and academically rugged. Yet forces of disruption undermined many of the earlier premises. The concept became more eclectic. Traits went beyond the familiar motivation and fellowship aura, time dimension became fluid and culture began to feature heavily in leaders' performance etc. All in all classic concept parameters began to fade.

Demonstration of leadership today is closely associated with individual perspective and individual exercise of control. Perspective and control take the issue out of the traditional single-track focus on the leader's behaviour or traits to the broader context of the leader as an individual, the followers as players and events as disruptive forces. Perspective embodies vision and desire to achieve. Control connotes locus and management of self. A propensity to lead is derived from this analysis. (El Namaki, 2017)

\section{Control}

Today's managerial control parameters address the issue of "where we plan to be "instead of "where we ought to be". Strategies, consequently, focus on improving an established position instead of the search for a better "fit" within a disrupted arena.

The concept of management control has failed in more than one way. Management control systems are designed to cope with changes of a limited magnitude, not the bold disruptive thrust that we are witnessing today. Control standards are more frequently than not blurred as they relate to an increasingly irrelevant past instead of the prospect. This makes it difficult to discriminate between conducive and nonconducive $r$ performance. And a measure of uncertainty as to whether the deviation in 
performance is due to the activity is out of control or due to the improperly set standards. Add to that information volume and flow. The trend towards too much information is as harmful to control, as incomplete information. (Raelin J, 2011).

\section{New strategic thinking premises}

Failure of many key strategic thinking concepts coupled with the rapid emergence of new technologies is leading to the rise of new or novel thrust concepts. The process is driven by a myriad of previously unknown forces from artificial intelligence and data dynamics to the internet of things and cognitive computing.

\section{Scenario building: Predictive analytics}

Predictive analytics are providing a valid substitute to open-ended environmental scanning inherent in the process of scenario building

Predictive analytics is a form of technology that makes predictions about certain unknowns in the future. It draws on a series of techniques to make these outcomes, including artificial intelligence (AI), data mining, machine learning, modelling, and statistics. It extracts information from data and uses it to predict trends and behaviour patterns. Predictive analytics uses statistics and modelling techniques to project future performance resorting to models like decision trees, regression, and neural networks. These models trace relationships, patterns, and structures in data. Those can be used to trace correlations between data and possible outcomes. (SAS."Predictive Analysis).

Figure 2: Predictive Analytics

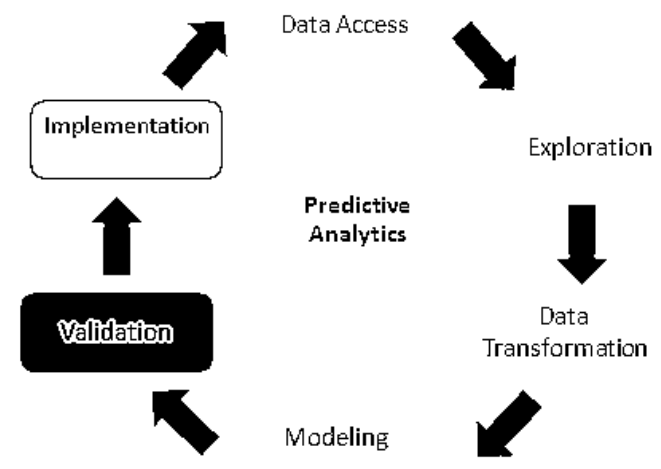

Source:http:/ / michaelencode.com/presentations /2014-10-06-big-data/

\section{Strategy formulation: Data-driven strategies}

Data-driven strategy formulation models will become an essential element of the new strategic thinking framework.

Those are models relying on an analytical data-based foundation supportive of corporate strategic directions. It is an analytics and not the logic or intuition of the past. Data is viewed as an asset with a clear link to a business impact. And as a mode for better strategies and better business decisions. They predict and optimize business outcomes. All of that assumes access to the right data and to a data resource 
beyond limited company reach e.g. social media or data flows from sensors, monitored processes and external sources. It also assumes an ability to build models that could predict and optimize business outcomes within a data culture.

\section{Strategic thinking models: Function specific arenas}

Technology disruption is inducing a radical shift in product development, a shift from the product to the function.

\section{Figure 3: Product function}

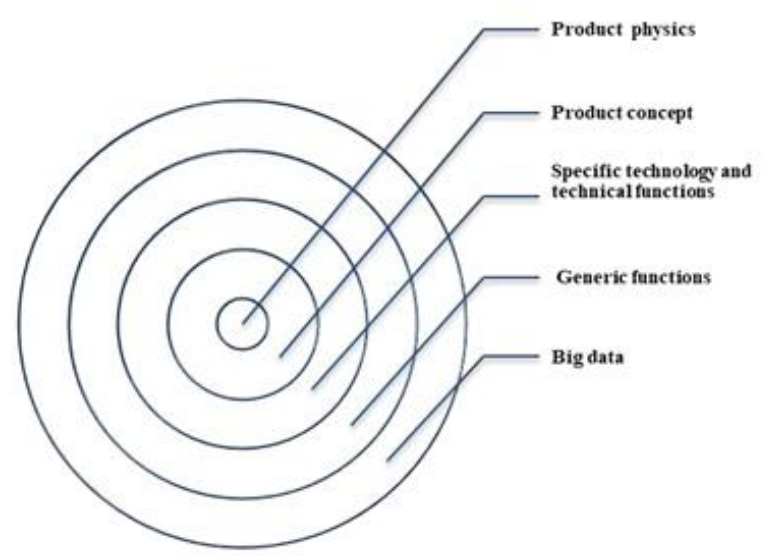

Source: Belu et al, 2011

Product function connotes product mission within an environment. Product function analysis develops a function structure or an abstract model of the product, or product concept, without the material features of shape, dimension or material. It provides a link with the environment where the product is born, used and abandoned. (Belu et al, 2011). Disruptive technology will lead to a shift from product to function. Strategy formulation models as BCG's will have to develop new parameters as a consequence. "We need to think of strategy and competition in terms of competitive arenas, not industries. An arena represents a chunk of resources controlled by different stakeholders - customers, certainly, but others too" (McGrath, 2019)

\section{Top management competencies: Competitive cognition}

Competitive cognition will constitute a novel element in top management competencies.

The term "competitive cognition" refers to the framework within which competitive knowledge is continuously acquired, used and retained. It is the process of making sense of the competitive environment (Walker et al, 2005). Through repeated exposure to rivals, executives learn the attributes and strategies of competitors and form mental representations of a given rival, then assign the target competitor to a category, using that classification as a guide to direct future actions. (Clark and Montgomery, 1999). Blind spots in competitive cognition and outmoded mental models can explain empirically observable phenomena such as industry overcapacity, the failure of new entries and acquisition overpayment. Industries are actually created through a shared interpretation of reality among business rivals. Rather than defining competitors on an 
individual basis, executives assign themselves to a competitive category (Porac and Thomas, 1990))

\section{Problem-solving: Diagnostic data analysis}

Diagnostic data analysis will provide a firm foundation for problem identification and problem-solving.

Diagnostic analytics constitute a thorough penetration of data in order to search for constraints and identify insights. It explores a possible link between outcomes and possible drivers. Put differently it relates problem areas to identifiable symptoms.

Diagnostic analytics is usually performed using such techniques as data discovery, drill-down, data mining, and correlations. In the discovery process, analysts identify the data sources that will help them interpret the results. Drilling down involves focusing on a certain facet of the data or particular widget. Data mining is an automated process to get information from a massive set of raw data. And finding consistent correlations pinpoint the parameters of the investigation (https://www.sisense.com/).

\section{Strategic behaviour: Competitive synergy}

Dynamic synergy analysis is a process whereby future driving forces of two companies are juxtaposed in order to identify areas of synergy and create a foundation for crosscompany strategic behaviour.

Synergy connotes, in this case, the interaction between two or more forces in a way that leads to a combined output that is greater than the sum of the individual components. Future driving forces could be capital-related, technology-related or productivity-related. Capital could become a driving force if capital markets are mature enough to create a dynamic force. Capital market maturity here is measured in terms of instruments, institutions, players, policies and flows. The technology could become a driving force if company parameters of technological innovation measure up to industry innovation standards. Those standards could relate to the volume of patents and patent product and process conversion. Productivity is a dependent function depending on capital and technology inputs.

\section{Strategic control: Implicit learning}

Implicit learning will provide a medium for strategic control or control against the potential as opposed to control by historical standards.

The key question in strategic control is: are goals in line with potential? Many goals are deduced or extrapolated and bear, in reality, little relevance to the 'true' potential of the organization. There are several ways to identify this potential. One of them is implicit learning. Implicit human long term memory performs "implicit learning", a form of learning that occurs without the individual's awareness. (Curran and Schacter, 2001).

Could business organizations develop an ability to learn implicitly and derive creative strategies from this implicit learning? One could hypothesize that In very much the same way that the human brain resorts to implicit learning to enhance cognitive competencies, executives and corporations could resort to implicit learning to enhance 
the scope, depth and reach of strategic thinking. And identify the potential. And in very much the same way that human brain enhancement of cognitive capacities comes through the growth of new neurons, executives and corporations could enhance their strategic thinking potential by enhancing their organizations' implicit memory or exposure to silent signals and stimuli originating from beyond the organizations' immediate periphery (El Namaki, ).

\section{Academic implications}

This new era will demand a fundamental shift in reference material, research streams, faculty competencies, and industry links and, of course, communication. Implications for the strategic thinking curriculum are summarized in the following table. The curriculum will have to accommodate much of the referred to innovations. Communicating the concept will require new modes. And translating the material into applied business tools will demand thorough exploration.

Figure 4: Endgame strategic thinking substitutes

\begin{tabular}{|c|c|c|}
\hline Area & Concepts & Subjects \\
\hline $\begin{array}{c}\text { Conceptual } \\
\text { framework for } \\
\text { strategic thinking }\end{array}$ & - $\quad$ The system & $\begin{array}{c}\text { Technology induced strategic } \\
\text { thinking model }\end{array}$ \\
\hline Strategy design & $\begin{array}{l}\text { - } \text { The } \\
\text { environment } \\
\text { - } \text { Strategic } \\
\text { design } \\
\text { models } \\
\text { - Strategies }\end{array}$ & $\begin{array}{c}\text { - Data analytics } \\
\text { - Data diagnostics } \\
\text { - Data driven strategic thinking } \\
\text { Strategic shift from product to } \\
\text { function } \\
\text { - Competitive synergy }\end{array}$ \\
\hline $\begin{array}{l}\text { Top management } \\
\text { role }\end{array}$ & $\begin{array}{c}\text { Vision } \\
\text { Competencies }\end{array}$ & $\begin{array}{l}\text { - Vision within AI frameworks } \\
\text { - Competitive cognition } \\
\text { - Cognitive computing } \\
\text { Leadership achievement and } \\
\text { control } \\
\text { - Dynamic cognition } \\
\end{array}$ \\
\hline Control & Strategic control & - Diagnostic analytics \\
\hline
\end{tabular}

There is also the serious need for rugged research in new dimensions of strategic thinking. Research that explores the "thrust" concepts and puts them within a coherent strategic thinking framework. Research that will become eclectic in nature as issues and concepts of 
Strategic thinking will cross science boundaries and relate to other sciences from neurology to psychology

Many a competency will also be reviewed and adjusted as a result of those new fields of strategic thinking. Some of those will relate to publications and others to delivery mechanisms.

\section{Summary and conclusions}

Powerful forces of disruption are penetrating the core concepts of strategic thinking and the strategy education industry.

Traditional strategic thinking literature and instruction material rest on a solid base of concepts developed by authors from Ansoff and Drucker to Porter, Mintzberg and Prahalad. Their concepts lasted for decades and their literature is a standard feature of business school strategy teachings until this very day. The generic and functional disruptive challenge posed by a broad mix of boundary-breaking technologies, norm shaking sociology, rule-breaking economics and unsettling political shifts, have all gone a long way towards introducing a new paradigm.

One of those disruptive impacts referred to above is the emergence of what we may term "end game "strategic thinking concepts that have lost relevance and subsided. Those include five force analysis, competitive advantage, scenario building, strategy formulation models and management control among others. A new wave of new concepts is rapidly replacing those. They include data-driven strategies, cognitive competition and data diagnostics analysis among others.

This shift will have a far-reaching impact going all the way from research directions to strategy curriculum design and strategic thinking competencies.

\section{References}

1. Belu, N, et al (2011)." Aspects on applying of functional analysis method to products design and its relationships with other various design methods". Annals of the Oradea University. Fascicle of Management and Technological Engineering. XX (X), 2011/2. 10.15660/AUOFMTE.2011-2.2304.

2. Boskin, M J (1987) "Reagan and the US Economy. The Successes, Failures, and Unfinished Agenda", ICEG.997 Kluwer Academic Publishers

3. Clark B, Montgomery D "Managerial Identification of Competitors", First Published July 1, 1999, Research Article https://doi.org/10.1177/002224299906300305 Journal of Marketing

4. Denning S, "It's Official! The End of Competitive Advantage", Journal of Global Competitiveness, 24(1), 51-58.

5. El Namaki, M (2017), "Disruption and the Changing Concept of Leadership ", International Journal of Management and Applied Research

6. El Namaki, M (2018), "Disruption in Business Environments: A Framework and Case Evidence ", International Journal of Management and Applied Research, Vol. 5, No. 1, pp. 1-7. https://doi.org/10.18646/2056.51.18-001

7. El Namaki, M (2014). How damaged are investment capital markets today? Competitiveness Review: An International Business Journal incorporating Jun 2, 2013,03:00pm EDT 
8. El Namaki M (2019), Could Business Organizations Simulate the Brain's Implicit Learning Process? International Journal of Management and Applied Research, 2019, Vol. 7, No. 1

9. Finlay, S (2014). Predictive Analytics, Data Mining and Big Data. Myths, Misconceptions and Methods. Basingstoke: Palgrave Macmillan. ISBN 978-1-13737927-6.

10. Martin Reeves, Sandy Moose, and Thijs Venema "BCG Classics Revisited: The Growth Share Matrix"

11. Meyer R, Volbeerda H. Porter H, "On corporate strategy", F A J van den Bosch and A P de Man (Eds) Perspectives on Strategy 25-33 (C)

12. McGrath, $\mathrm{R}$ "The End of Competitive Advantage", HBR, August 07, 2013

13. McGrath R, "Think competitive arenas, not industries", September 2019 -, Duke Corp Education.

14. Nilofer M, Why Porter's Model No Longer Works, HBR February 29, 2012.

15. Porter, M. "The Five Competitive Forces that Shape Strategy", Harvard Business Review, January, 2008, p.86-104

16. Porter, M. (1980) Competitive Strategy, Free Press, New York, 1980.

17. Porter, M. (1979) "How Competitive Forces Shape Strategy", Harvard Business Review, March/April 1979.

18. Raelin, Joseph A., The End of Managerial Control? (March 1, 2011). Group \& Organization Management, Vol. 36, No. 2, pp. 135-160, 2011, Available at SSRN: https://ssrn.com/abstract=1787684 or http://dx.doi.org/10.2139/ssrn.1787684 Vol. 4, No. 2, pp. 122-129. https://doi.org/10.18646/2056.42.17-010

19. Stonehouse, G "Competitive Advantage Revisited: Michael Porter on Strategy and Competitiveness", 2007, Journal of Management Inquiry.

20. Walker B, Kapelianis D and Hutt M, "The importance of properly identifying the strategies, and anticipating the actions, of rivals". MIT Sloan Management Review, July 15, 2005

21. https://www.sas.com/en_sg/insights/analytics/predictive-analytics.html

22. https://www.ibm.com/analytics/predictive-analytics

23.http://michaelencode.com/presentations/2014-10-06-big-data/ 